\title{
Immunohistochemistry of carcinoembryonic antigen: characterisation of cross-reactions with other glycoproteins
}

\author{
P. ISAACSON AND MARY A. JUDD ${ }^{1}$ \\ From the Department of Pathology, Faculty of Medicine, General Hospital, Southampton
}

SUMMARY In the course of demonstrating carcinoembryonic antigen (CEA) in normal human small intestine cross-reactivity of specific antiserum against red blood cells, vascular endothelium, and Paneth cell granules was noted. Pretreatment of sections with periodic acid eliminated these cross-reactions without affecting the staining of CEA, indicating that the antigenic determinants shared between CEA and other glycoproteins are in the carbohydrate portion of the molecules. These findings emphasise the caution with which immunohistochemical results should be regarded even when they are apparently well controlled.

Immunohistochemical demonstration of carcinoembryonic antigen (CEA) in tissues has been largely concerned with the identification of malignant colonic epithelium (Isaacson and Le Vann, 1976). Successful application of the procedure requires that antibody to human CEA can be used at a high dilution, close to that point at which a positive reaction in tumour tissue is no longer obtainable. This is because only at these high dilutions can quantitative differences in tissue CEA be demonstrated, the concentration being much higher in malignant tissue (Khoo et al., 1973). In a recent study of CEA localisation in normal human small intestine (Isaacson and Judd, 1977), the object was not to demonstrate quantitative differences in tissue CEA and, consequently, very high dilutions of antiCEA were not used. At these lower dilutions of antibody, and sometimes persisting into quite high dilutions, confusing, apparently specific, staining of red blood cells and vascular endothelium was noted. The intensity of this staining varied from case to case and with the vascularity of the tissue under study. Accordingly, an investigation was made into the nature of the cross-reaction with red blood cells and a method sought that would eliminate it.

Pretreatment of tissue sections with periodic acid

'Some of the work described in this paper will form part of a thesis for Fellowship of the Institute of Medical Laboratory Scientists.

Received for publication 28 February 1977 eliminated the positive staining of red blood cells and endothelium without significantly affecting the staining of CEA. Paneth cell granules, initially thought to stain specifically for CEA, were likewise affected by periodic acid. The investigation established new criteria for immunohistochemical demonstration of CEA and emphasised the caution with which immunohistochemical results should be viewed, even when apparently well controlled.

\section{Methods}

CEA AND ANTICEA

Purified CEA and specific goat antihuman CEA were obtained from the Chester Beatty Research Institute, London. The methods of preparation and immunochemical characteristics have been previously described (Darcy et al., 1973; Tuberville et al., 1973). The CEA was free of non-specific cross-reacting antigen (NCA) and showed immunological identity with CEA from the Montreal and Duarte groups. The goat antiCEA gave a single reaction line when diffused against perchloric acid extracts of colonic carcinoma and, specifically, was free of antiNCA activity.

\section{ABSORPTION OF ANTISERA}

One $\mathrm{cm}^{3}$ of $\frac{1}{100}$ dilution of goat antiCEA in phosphate buffered saline (PBS) was absorbed overnigh 
Table Red blood celis used to investigate cross- reactivity of goat antihuman CEA. Cells 1-9 stained for CEA. Cells 10 and 11 used to absorb goat antiCEA

\begin{tabular}{|c|c|c|c|c|c|c|c|c|c|c|c|c|c|c|c|c|c|}
\hline \multirow[t]{3}{*}{ No. } & \multicolumn{16}{|c|}{ Phenotype } & \multirow{3}{*}{$\begin{array}{l}\text { Staining } \\
\text { intensity }\end{array}$} \\
\hline & \multirow[t]{2}{*}{$A B O$} & \multirow[t]{2}{*}{$R h$} & \multirow[t]{2}{*}{$M N$} & \multirow[t]{2}{*}{$S$} & \multirow[t]{2}{*}{$\bar{s}$} & \multirow[t]{2}{*}{$P^{1}$} & \multicolumn{2}{|c|}{$L u$} & \multirow[t]{2}{*}{$K$} & \multirow[t]{2}{*}{$k$} & \multicolumn{2}{|c|}{ Le } & \multicolumn{2}{|c|}{$F y$} & \multicolumn{2}{|l|}{$J k$} & \\
\hline & & & & & & & $a$ & $b$ & & & $a$ & $b$ & $a$ & $b$ & $a$ & $b$ & \\
\hline 1 & $\mathrm{O}$ & $\mathrm{R}_{1} \mathrm{R}_{1}$ & $\mathrm{MN}$ & + & + & $+t$ & - & & - & - & - & - & - & - & + & - & $\perp+$ \\
\hline 2 & $\mathrm{O}$ & $\mathbf{R}_{2} \mathbf{R}_{2}$ & $\mathbf{M N}$ & - & + & - & + & & - & + & - & - & - & - & + & - & \pm \\
\hline 3 & $\mathrm{O}$ & $R_{1} R_{2}$ & $\mathbf{M N}$ & $T$ & $\div$ & $t+$ & - & & + & + & - & + & - & $\div$ & + & - & $++\cdots$ \\
\hline 4 & $\mathrm{O}$ & $\mathrm{rr}$ & $\mathrm{N}$ & - & + & $+t+$ & - & & + & - & - & + & - & + & + & - & ++ \\
\hline 5 & $\mathrm{O}$ & $\mathrm{rr}$ & $\mathbf{M}$ & - & - & $++t$ & - & & + & + & $\therefore$ & - & - & - & + & + & $\perp$ \\
\hline 6 & $\mathrm{O}$ & $\mathrm{rr}$ & $\mathbf{M}$ & + & + & $+t+$ & - & & - & + & - & - & + & + & - & - & ++ \\
\hline 7 & $\mathrm{O}$ & $\mathbf{R}^{1} \mathbf{r}$ & $\mathbf{M N}$ & - & + & + & - & & + & + & - & - & - & + & + & + & $+t$ \\
\hline 8 & O & $\mathbf{R}^{11} \mathbf{r}$ & MN & - & + & ++ & - & & - & $T$ & - & - & - & - & .. & + & ++ \\
\hline 9 & $\mathbf{A B}$ & & & & & & & & & & & & & & & & + \\
\hline $\begin{array}{l}10 \\
11\end{array}$ & $\begin{array}{l}A_{1} \\
O\end{array}$ & $\mathbf{R}^{1} \mathbf{r}$ & $\mathbf{M}$ & - & + & $\begin{array}{l}+t+1 \\
-\end{array}$ & - & & - & - & - & - & + & - & & & \\
\hline
\end{tabular}

with $0.3 \mathrm{mg}$ purified CEA. A further $1 \mathrm{~cm}^{3}$ of $\frac{1}{100}$ goat antiCEA was absorbed overnight at $4^{\circ} \mathrm{C}$ with $1 \mathrm{~cm}^{3}$ of washed human red blood cells of known phenotype (Table).

\section{HISTOLOGICAL SECTIONS}

Sections of normal human small intestine and positive control sections of colon carcinoma were obtained fresh and routinely processed into paraffin blocks as described elsewhere (Isaacson and Judd, 1977). A panel of washed human red blood cells was obtained from the Wessex Regional Blood Transfusion Service; the cells were suspended in plasma which was then clotted, and the clots containing the red blood cells fixed in formol saline and processed into paraffin blocks.

\section{STAINING METHOD}

Although the staining method for CEA has been previously described, it will be briefly summarised again, as small variations in the technique produced significantly different results. The sequential steps were as follows:

1. $5 \mu \mathrm{m}$ sections were deparaffinised to alcohol.

2. Endogenous peroxidase was inhibited using $0.5 \% \mathrm{H}_{2} \mathrm{O}_{2}$ in methanol for 10 minutes followed by three washes in PBS at $\mathrm{pH} 7 \cdot 3$.

3. Sections were flooded with normal horse serum for 10 minutes to block non-specific staining by the peroxidase conjugated horse antigoat serum.

4. Goat antiCEA in appropriate dilution ${ }^{2}$ was

\footnotetext{
${ }^{2}$ The actual dilution of goat antiCEA used varied according to the activity of the horse antigoat peroxidase conjugate. With a highly active conjugate, as was the case during most of the present investigation, a dilution of $\frac{1}{200}$ goat antiCEA was used with positive staining of small intestine and colon carcinoma persisting maximally to a dilution of $\frac{1}{3200}$.
}

applied for 30 minutes followed by three washes in PBS.

5. Sections were flooded with $1 / 5$ normal horse serum for 10 minutes.

6. Horse antigoat peroxidase conjugate ${ }^{3}$, prepared by the method of Nakane and Kawaoi (1974) was applied for 30 minutes.

7. The peroxidase was 'developed' using 3, 3' diaminobenzidine (DAB) according to the method of Graham and Karnovsky (1966).

8. After rinsing in distilled water slides were counterstained with haematoxylin, dehydrated, and mounted in DPX.

Two sections of small intestine and a section of colon carcinoma were stained substituting the various absorbed antisera for goat antiCEA (step 4). Each section studied was also stained substituting normal goat serum for goat antiCEA.

\section{Results}

\section{UNMODIFIED STAINING PROCEDURE}

There was a strong positive staining reaction for CEA over the surface of small intestinal villous epithelium, often intensified as a lumenal border in the crypts (Fig. 1). Goblet cells often stained and Paneth cells stained strongly (Fig. 5). Red blood cells and endothelium stained positively with considerable variation in intensity from section to section, the positive staining almost always fading before that of the epithelium with increasing dilution of antiCEA. Sections of colonic carcinoma used as a positive control stained positively, as previously described (Isaacson and Le Vann, 1976), with red blood cell and blood vessel staining becoming evident at higher concentrations of goat antiCEA (Fig. 7). When normal goat serum was substituted

\footnotetext{
${ }^{3}$ Horse antigoat serum obtained from Burroughs Wellcome as donkey antisheep serum.
} 


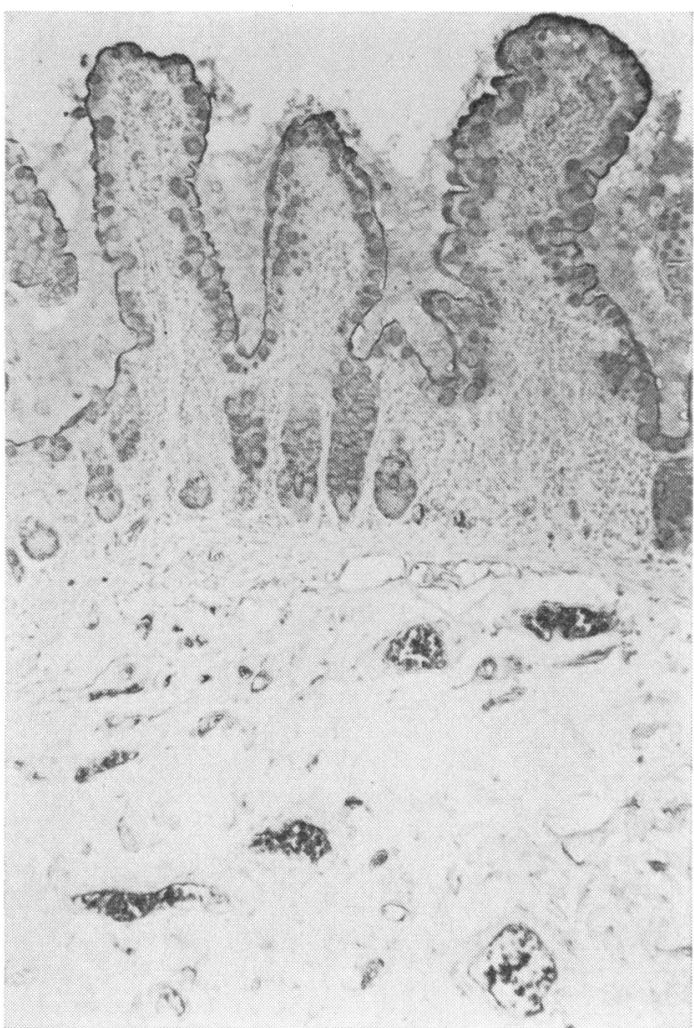

Fig. 1 Normal human ileum stained for CEA. Note staining of epithelial surface, goblet cells, and crypt lining. There is also some staining of surface mucin. Red blood cells and vascular endothelium stain strongly positive. $\times 100$.

for goat antiCEA all sections were negative. Endogenous peroxidase within red blood cells and neutrophils was well inhibited by the $\mathrm{H}_{2} \mathrm{O}_{2}$ in methanol.

The results of staining sections of red cells from the transfusion panel are given in the Table. Variation in phenotype yielded variation in staining intensity and, while no sections were entirely negative, $\mathbf{P}^{1}$ negative cells stained only very lightly. Sections stained with normal goat serum substituted for goat antiCEA were uniformly negative.

Absorption of goat antiCEA with CEA abolished all positive staining in small intestine and colonic carcinoma including that of endothelium red cells and Paneth cells (Fig. 2).

Absorption of goat antiCEA with human red cells, both $\mathbf{P}^{1}$ positive and negative (Table), caused some reduction in epithelial cell staining of small intestine and colon carcinoma with prompt disappearance of endothelial, red blood cell, and Paneth cell staining (Figs. 3, 8).
EFFECT OF PERIODIC ACID

Substitution of $1 \%$ periodic acid for $\mathrm{H}_{2} \mathrm{O}_{2}$ in methanol in step 2 of the staining procedure not only inhibited endogenous peroxidase of red blood cells and neutrophils but abolished endothelial, red blood cell, and Paneth cell staining even at high concentrations of antiserum (Figs. 3,6). Staining of the epithelial surface of the small intestine, the lumenal border in the crypts, and the goblet cells was unaffected, as was the staining of colonic carcinoma. Positive staining persisted into equally high dilutions of goat antiCEA.

\section{Discussion}

Contamination of some CEA and antiCEA preparations with the closely related antigen NCA and antiNCA respectively has been noted (von Kleist $e t$ $a l .$, 1972). The CEA and antiCEA used in this investigation were free of NCA and antiNCA activity and, in any event, NCA is found in CEA positive epithelia

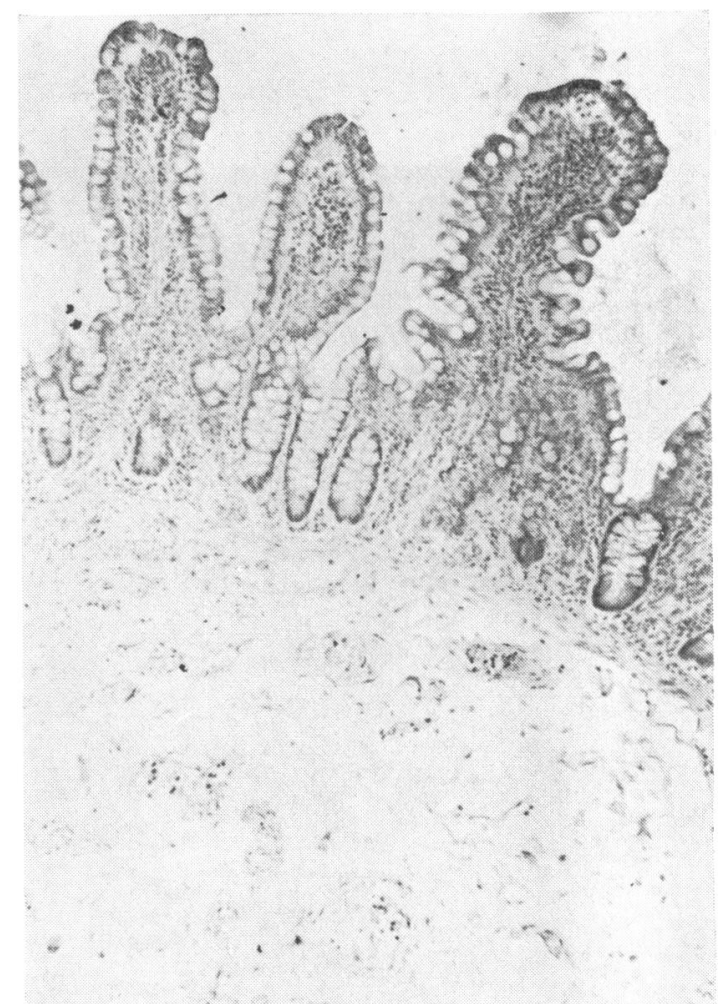

Fig. 2 Normal human ileum stained for CEA after absorption of goat antiCEA with purified CEA. All positive staining is ablolished. $\times 100$. 


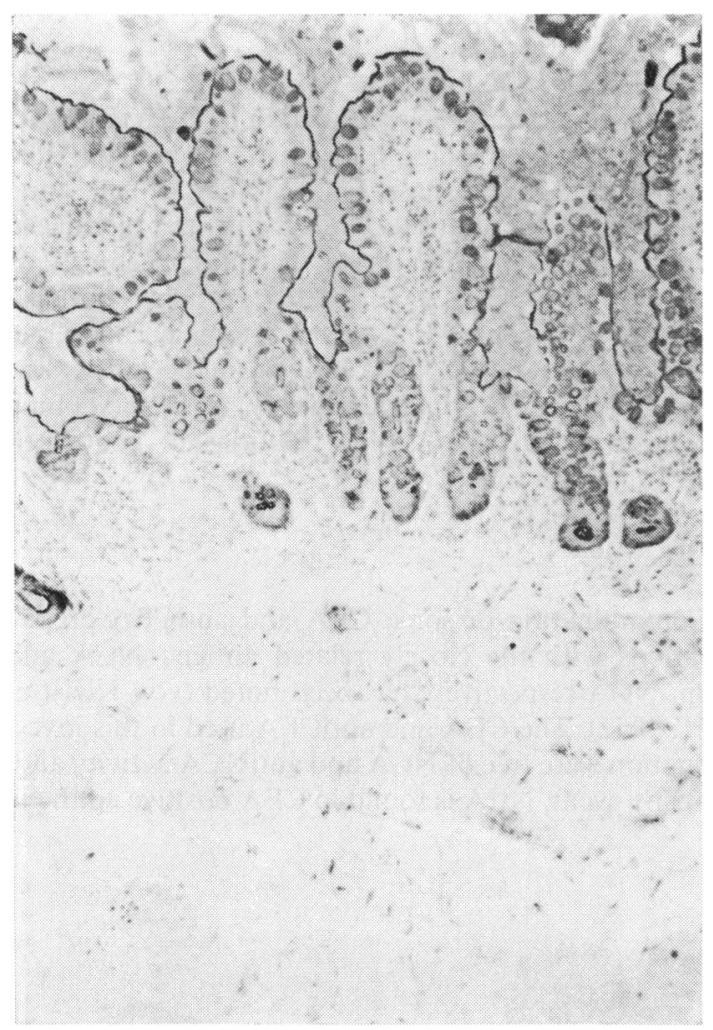

Fig. 3

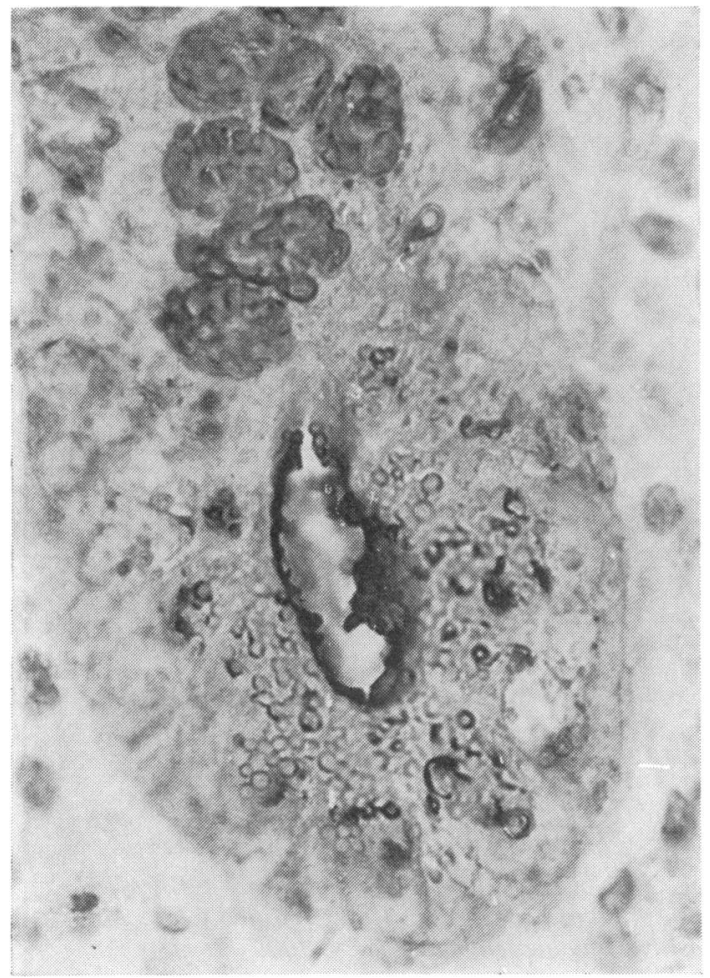

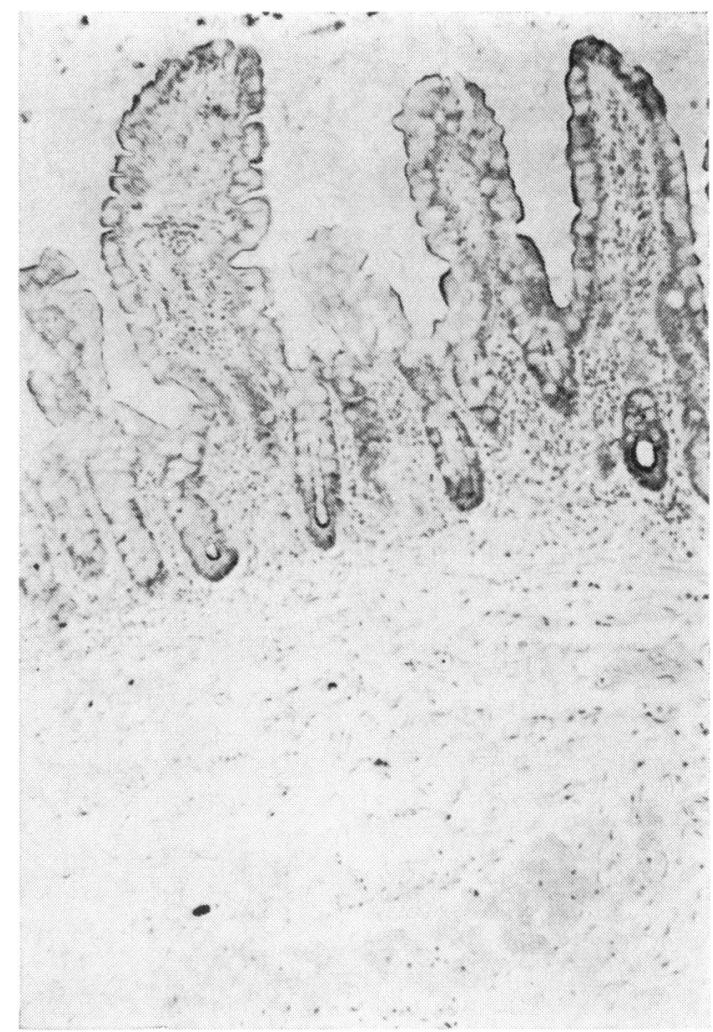

Fig. 4

Fig. 3 Normal human ileum stained for CEA after treatment of sections with $1 \%$ periodic acid. Positive staining of epithelieal surface, goblet cells, and crypt lining persists. Red blood cells and vascular endothelium no longer stain. $\times 100$.

Fig. 4 Normal human ileum stained for CEA after absorption of goat antiCEA with human red blood cells. Surface epithelial and goblet cell staining are reduced in intensity. Red blood cell and endothelial staining are abolished. $\times 100$.

Fig. 5 High power view of small intestinal crypt stained for CEA. Goblet cells, crypt border, and Paneth cell granules stain positively. $\times 1000$.

Fig. 5 


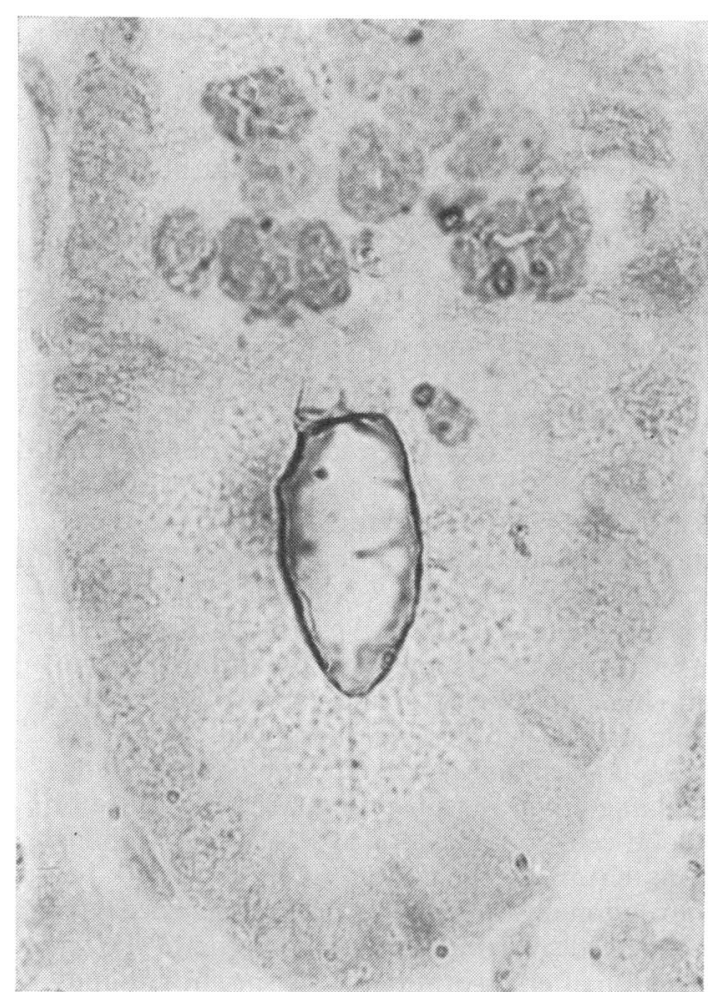

Fig. 6

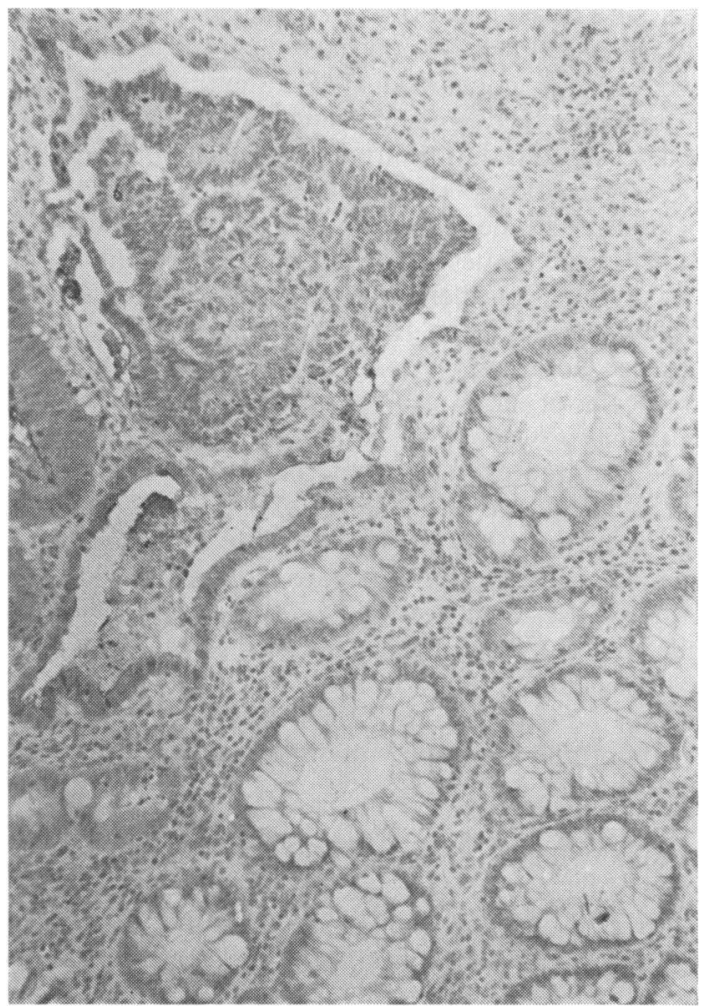

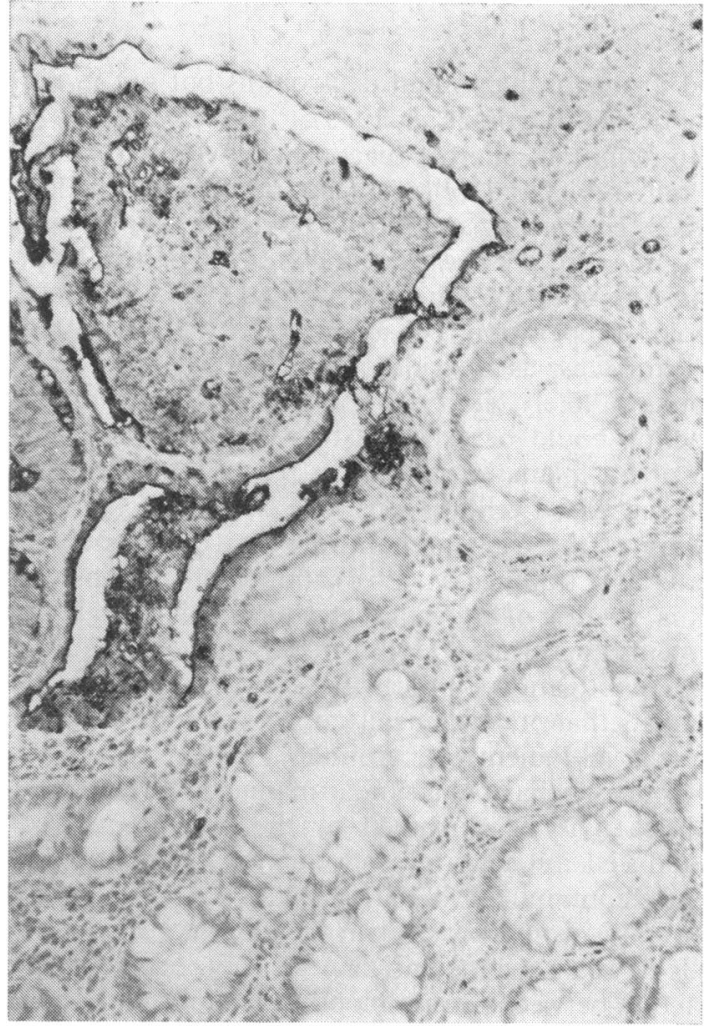

Fig. 7
Fig. 6 Small intestinal crypt stained for CEA after treating section with $1 \%$ periodic acid. Goblet cells and crypt border stain positively but Paneth cell staining is abolished. $\times 1000$.

Fig. 7 Colon carcinoma and adjacent normal mucosa stained for CEA. There is strong staining of lumenal border of malignant glands with staining of red blood cells and vascular endothelium. $\times 100$.

Fig. 8 Same section as Fig. 7 stained for CEA after absorption of goat antiCEA with human red blood cells. Positive staining of malignant glands is reduced but not abolished. Red blood cell and endothelial staining is abolished. $\times 100$. 
and in macrophages and neutrophils but not in red blood cells (Burtin et al., 1975).

Immunological cross-reactivity between CEA and certain red blood cell antigens has been well described (Holburn et al., 1974). The red blood cell antigens involved are related to those of the patient from whose tumour the CEA was extracted, so that in a pooled preparation, broad cross-reactivity with red cell antigens, as is evident from the present study, would be likely, although the intensity of the crossreaction could be expected to vary. There are two possible explanations for cross-reaction of antiCEA and red blood cell antigens, one being the contamination of the CEA preparation with red blood cell material (Cooper et al., 1974) and the other being the actual sharing of antigenic determinants by the glycoproteins concerned ((Holburn et al., 1974). The present investigation supports the latter explanation and suggests that other tissue glycoproteins such as those present in Paneth cell granules (Taylor and Flaa, 1964) may behave in a similar manner. The endothelial reactivity is explained by the presence of red blood cell antigens on endothelium (Eisen, 1976). While contamination of purified CEA is a possibility, this would not explain the ability of red blood cells to absorb some antiCEA activity, or the crossreaction between certain blood group antibodies and CEA observed by Holburn et al. (1974) using radioimmunoassay. Endothelial staining has been observed by other workers using immunofluoresence and an antiserum from a source different from ours (Unger, 1976) and we have observed red blood cell and endothelial staining with commercially prepared rabbit antiCEA ${ }^{4}$. Other reports of immunohistochemical demonstration of CEA using a peroxidase technique have not mentioned cross-reactivity with red blood cells (Primus and Wang, 1975; Huitric et al., 1976; Goldenburg et al., 1976; Isaacson, 1976; Isaacson and Le Vann, 1976). In some cases this is because antiserum was used at a dilution close to the point at which no reaction was obtainable and in others because endogenous red blood cell peroxidase was not inhibited, thus masking any cross-reaction with red blood cells and endothelium.

The results of treating sections with periodic acid are of great interest, as this abolishes cross-reaction of antiCEA with red blood cells, endothelium, and Paneth cell granules, leaving the CEA specificity intact. The action of $1 \%$ periodic acid on tissues is to convert carbohydrates to aldehydes (by this action endogenous peroxidase is also destroyed) and this presumably interferes with the antigenic properties of the carbohydrate portion of glycoproteins leaving that of the protein component intact. Thus it seems

${ }^{4}$ Dakopatts. that the antigenic determinants shared between CEA, red blood cell antigens, and other glycoproteins reside in periodate sensitive carbohydrate portions of the molecules and an antiserum prepared against CEA continues to react with the protein portion of the molecule after the carbohydrate portion has been destroyed. Westwood and Thomas (1975) were able to remove up to $50 \%$ of the carbohydrate portion of CEA by treatment with periodate and showed no loss of antigenic activity as measured by radioimmunoassay. While the effect of treating tissues with $1 \%$ periodic acid is not necessarily similar, it would be of interest to see if the crossreaction of blood group antibodies with CEA, as demonstrated by Holburn et al. (1974), persisted with periodate treated CEA. Absorption of antiCEA with red blood cells should remove from the antiserum those antibodies to the carbohydrate determinants shared between red blood cells and CEA. The results of diminished, but not abolished, epithelial staining coupled with prompt disappearance of red blood cell, endothelial, and Paneth cell staining indicate that this is the case.

Conventionally, immunohistochemical procedures are controlled by demonstrating abolition of the tissue reaction after absorption of the specific antibody with specific antigen. Had we not inhibited endogenous peroxidase the obviously non-specific staining of red blood cells would have been masked and we would have concluded that Paneth cells, and later, perhaps other tissue elements, contained CEA. Thus it is essential that pretreatment of sections with $1 \%$ periodic acid be performed in all future immunohistochemical studies of CEA. Actual extraction of pure CEA from tissues as carried out by Goldenburg et al. (1976) is another way of ensuring that it is indeed CEA that is being demonstrated but extraction studies are not always possible, particularly when isolated cells or small groups of cells are involved. With the improvement of immunoperoxidase techniques, immunohistochemistry is now a rapidly expanding field and the validity of the results is of great importance. The importance of pure antigens, avid antisera, and good negative controls using absorbed antisera has been stressed (Heyderman and Neville, 1976). None of these measures will exclude spurious results caused by cross-reacting antigens. These can be detected only by intensive testing of the method, under a variety of conditions, on a wide range of tissues.

We are indebted to Professor A. Munro Neville for supplies of CEA and antiCEA, to Dr D. S. Smith for the panel of washed human red blood cells, to Professor D. H. Wright for his advice, and to Mrs Oliver Huber for secretarial assistance. 


\section{References}

Burtin, P., Quan, P. C., and Sabine, M. C. (1975). Nonspecific cross-reacting antigen as a marker for human polymorphs, macrophages and monocytes. Nature, 255, 716.

Cooper, A. G., Brown, M. C., Kirch, M. E., and Rule, A. H. (1974). Relationship of carcinoembryonic antigen to blood substances $\mathrm{A}$ and $\mathrm{i}$ : evidence that the antigenic sites are on different molecules. Journal of Immunology, 113, 1246-1251.

Darcy, D. A., Turberville, C., and James, R. (1973). Immunological study of carcinoembryonic antigen (CEA) and a related glycoprotein. British Journal of Cancer, 28, 147160.

Eisen, H. N. (1976). Microbiology, 2nd edn. p. 600. Edited by B. D. Davis, R. Dulbecco, H. N. Eisen, H. S. Ginsberg, and B. W. Wood, Jr. Harper and Row: Hagerstown.

Goldenberg, D. M., Sharkey, R. M., and Primus, F. J. (1976). Carcinoembryonic antigen in histopathology: immunoperoxidase staining of conventional tissue sections. Journal of the National Cancer Institute, 57, 11-22.

Graham, R. C., and Karnovsky, M. J. (1966). The early stages of absorption of injected horseradish peroxidase in the proximal tubules of mouse kidney-ultrastructural cytochemistry by a new technique. Journal of Histochemistry and Cytochemistry, 14, 291-302.

Heyderman, E., and Neville, A. M. (1976). Immunoperoxidase localisation of pregnancy protein. Lancet, 2, 744.

Holburn, A. M., Mach, J.-P., MacDonald, D., and Newlands, M. (1974). Studies of the association of the A, B. and Lewis blood group antigens with carcinoembryonic antigen (CEA). Immunology, 26, 831-843.

Huitric, E., Laumonier, R., Burtin, P., von Kleist, S., and Chavanel, G. (1976). An optical and ultrastructural study of the localization of carcinoembryonic antigen (CEA) in normal and cancerous human rectocolonic mucosa. Laboratory Investigation, 34, 97-107.

Isaacson, P. (1976). Tissue demonstration of carcinoembry- onic antigen (CEA) in ulcerative colitis. Gut, 17, 561-567.

Isaacson, P., and Le Vann, H. P. (1976). The demonstration of carcinoembryonic antigen in colorectal carcinoma and colonic polyps using an immunoperoxidase technique. Cancer, 38, 1348-1356.

Isaacson, P., and Judd, M. A. (1977). Carcinoembryonic antigen (CEA) in the normal human small intestine: a light and electron microscopic study. Gut, 18, 786-791.

Khoo, S. K., Warner, N. L., Lie, J. T., and MacKay, I. R. (1973). Carcinoembryonic antigenic activity of tissue extracts: a quantitative study of malignant and benign neoplasms, cirrhotic liver, normal adult and fetal organs. International Journal of Cancer, 11, 681-687.

Nakane, P. K., and Kawaoi, A. (1974). Peroxidase-labeled antibody. A new method of conjugation. Journal of Histochemistry and Cytochemistry, 22, 1084-1091.

Primus, F. J., and Wang, R. H. (1975). Detection of carcinoembryonic antigen in tissue sections by immunoperoxidase. Journal of Immunological Methods, 8, 267-276.

Taylor, J. J., and Flaa, R. C. (1964). Histochemical analysis of Paneth cell granules in rats. Archives of Pathology, 77, 278-285.

Turberville, C., Darcy, D. A., Laurence, D. J. R., Johnson, E. W., and Neville, A. M. (1973). Studies on carcinoembryonic antigen (CEA) and a related glycoprotein, CCEA-2. Preparation and chemical characterisation. Journal of Immunochemistry, 10, 841-843.

Unger, A. (1976). Personal communication.

von Kleist, S., Chavanel, G., and Burtin, P. (1972). Identification of an antigen from normal human tissue that crossreacts with the carcinoembryonic antigen. Proceedings of the National Academy of Sciences (Washington), 69, 2492 2494.

Westwood, J. H., and Thomas, P. (1975). Studies on the structure and immunological activity of carcinoembryonic antigen-the role of disulphide bonds. British Journal of Cancer, 32, 708-719. 